\title{
Microwave-assisted Hirao reaction: recent developments
}

\author{
Goutam Brahmachari ${ }^{1}$
}

Received: 6 April 2015/Accepted: 14 August 2015/Published online: 30 August 2015

(C) Springer International Publishing 2015

\begin{abstract}
Organic molecules containing phosphorus, now, constitute a major branch of chemistry, and offer fascinating possibilities for their structural, synthetic, and mechanistic study as well as promising biological activities. Organophosphorus compounds find numerous potential applications in the areas of industrial, agricultural, and medicinal chemistry. Aryl- and vinyl-phosphonates are an important class of organophosphorus compounds with potential biological relevance. The Hirao reaction offers a way to access these compounds through phosphorus-carbon $(\mathrm{P}-\mathrm{C})$ cross-coupling of aryl and vinyl halides with $O, O$-dialkyl phosphites, and this reaction has attained a commendable development in many ways in regard to the diversity in the substrates, $>\mathrm{P}(\mathrm{O}) \mathrm{H}$ species, catalysts, and reaction conditions. The present article deals with such developments that occurred under the influence of microwave irradiation.
\end{abstract}

Keywords The Hirao reaction - Microwaves . Phosphorous-carbon cross-coupling - Aryl/vinylphosphonates $\cdot$ Phosphine oxides

\section{Abbreviations \\ DIEA $\quad N, N$-Diisopropylethylamine \\ DMF $\quad N, N$-dimethylformamide \\ DMSO Dimethyl sulfoxide}

This article is dedicated to Professor Srinivasan Chandrasekaran.

Goutam Brahmachari

brahmg2001@yahoo.co.in; goutam.brahmachari@visvabharati.ac.in

1 Laboratory of Natural Products and Organic Synthesis, Department of Chemistry, Visva-Bharati (a Central University), Santiniketan 731235, West Bengal, India

$\begin{array}{ll}\text { dppp } & \text { 1,3-Bis(diphenylphosphino)propane } \\ \mathrm{Et}_{3} \mathrm{~N} & \text { Triethylamine } \\ \mathrm{GR} & \text { Glucocorticoid receptor } \\ \text { MMP-2 } & \text { Matrix metalloproteinase-2 } \\ \text { MTB-GS } & \begin{array}{l}\text { Mycobacterium tuberculosis } \text { glutamine } \\ \text { synthetase }\end{array} \\ \mathrm{MW} & \text { Microwave } \\ \mathrm{Pd}\left(\mathrm{PPh}_{3}\right)_{4} & \text { Tetrakis(triphenylphosphine)palladium } \\ \mathrm{PTC} & \text { Phase-transfer catalysis }\end{array}$

\section{Introduction}

The chemistry of organophosphorus compounds is rich enough, and such chemical entities occupy a significant position among the plethora of organic compounds as far as their properties and applications are concerned [1]. Organophosphorus compounds find a wide range of applications in the areas of industrial, agricultural, and medicinal chemistry owing to their inherent biological and physical properties $[2,3]$. Phosphorus-carbon $(\mathrm{P}-\mathrm{C})$ bond formation, thus, remains a valid and active exercise in chemical research as a result of which new reactions are continuously being developed for the preparation of organophosphorus compounds such as substituted phosphonates and related derivatives of potential multifaceted interests [4-6]. The synthesis of arylphosphonates and related derivatives is a focus of interest these days [5]. Aryl phosphonates can be prepared by the Arbuzov reaction of trialkyl phosphites and aryl halides only under special conditions due to the lower reactivity of aryl halides [7, 8]. Later on, the Hirao reaction has appeared as the most suitable method for the synthesis of arylphosphonate derivatives [51]. Since the first report in 1980s, there has 
been a commendable development on this reaction, and the present article is restricted only to focus on the synthesis of diverse aryl- and vinyl-phosphonates and related derivatives by means of the microwave-assisted Hirao reaction. Microwave technique is regarded as one of the 'green tools' in organic synthesis [9], and the key benefit of using this technique is to accelerate reaction rate.

\section{The Hirao reaction}

In the early 1980s, Hirao and coworkers reported a phosphorus-carbon cross-coupling reaction of aryl- and vinyl halides with $O, O$-dialkyl phosphites in the presence of triethylamine $\left(\mathrm{Et}_{3} \mathrm{~N}\right)$ and catalytic amount of tetrakis(triphenylphosphine)palladium $\left[\mathrm{Pd}\left(\mathrm{PPh}_{3}\right)_{4}\right]$ to synthesize a variety of dialkyl aryl- and vinyl-phosphonates in good yields [10-12]. This reaction is now known as the Hirao reaction after the name of the inventor. The general representation of the Hirao reaction is shown in Scheme 1.

The Hirao reaction has now become an important $\mathrm{P}-\mathrm{C}$ bond forming method since its discovery about 35 years ago. On further development and modifications, this method constitutes the current state of the art in the synthesis of $\mathrm{P}-\mathrm{C}(\mathrm{sp} 2)$ bonds as documented in a number of reviews [13-15]. The Hirao reaction has been gradually extended to more aryl and vinyl derivatives and to variety of $>\mathrm{P}(\mathrm{O}) \mathrm{H}$ species, thus making available phosphonic, phosphinic and phosphine oxide derivatives as well [5].

\section{Mechanistic aspect of the Hirao reaction}

In their following report, Hirao and his group [12] also proposed a mechanism for the reaction. Palladium(0) is supposed to undergo oxidative addition with aryl-/vinyl halide to generate a palladium(II)-complex as the key intermediate. The dialkyl phosphite molecule then attacks the aryl-/vinyl-palladium(II) halide complex to afford the desired product, dialkyl aryl-/vinyl phosphonate, along with the formation of palladium(II) halide hydride. In the next step, this palladium(II) halide hydride reacts with triethylamine to regenerate palladium(0) species, thus, making itself available for another reaction cycle. The overall mechanistic path is delineated in Scheme 2.

\section{Application of microwave in the Hirao reaction: the benefits}

In recent years, application of microwaves to synthetic organic chemistry has become increasingly popular and attracted considerable practical [16-19] and theoretical attention [20]. The most common benefits from microwave irradiation are the considerable shortening of reaction times, thereby accelerating reaction rates, and the increase in the selectivities. However, the most valuable benefit is when a reaction can be carried out that is otherwise impossible under traditional thermal conditions. This may be the consequence of a so-called special microwave effect

Scheme 1 The Hirao reaction

\begin{tabular}{|c|c|c|c|c|}
\hline & O $\mathrm{OR}^{\prime}$ & catal $\mathrm{Pd}\left(\mathrm{PPh}_{3}\right)_{4}$ & & \\
\hline & 'OR' & $\mathrm{Et}_{3} \mathrm{~N}, 90^{\circ} \mathrm{C}, 0.2-30 \mathrm{~h}$ & 'OR' & $\mathrm{Et}_{3} \mathrm{~N} . \mathrm{HX}$ \\
\hline $\begin{array}{l}\text { (aryl or vinyl } \\
\text { halide) }\end{array}$ & $\begin{array}{l}\text { Dialkyl phosphite } \\
\text { (H-phosphonate) }\end{array}$ & $\begin{array}{l}\text { toluene (or no solvent } \\
\text { in few cases) }\end{array}$ & $\begin{array}{l}\text { Dialkyl aryl-/vinyl- } \\
\text { phosphonate }\end{array}$ & \\
\hline \multicolumn{3}{|c|}{$\mathrm{R}=\operatorname{aryl}$, vinyl; $\mathrm{X}=\mathrm{Br}, \mathrm{I}$} & (yield: $3-98 \%$ ) & \\
\hline $\mathrm{R}^{\prime}=\mathrm{Et}, n-\mathrm{B}$ & & & & \\
\hline
\end{tabular}

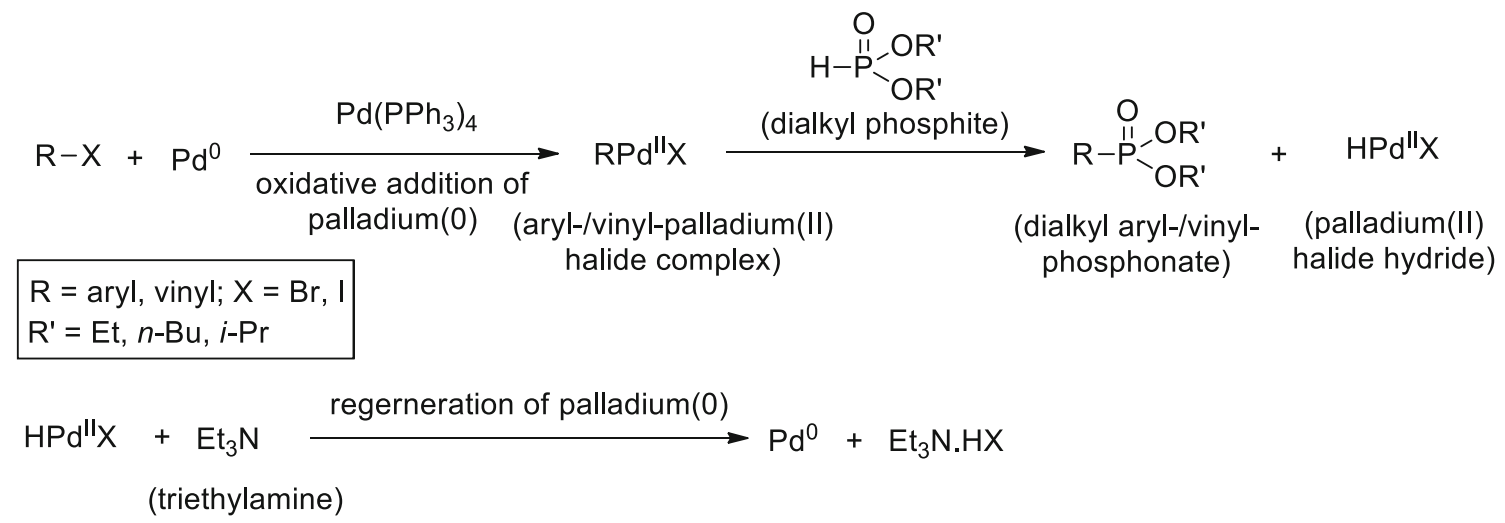

Scheme 2 Proposed mechanism for the Hirao reaction 

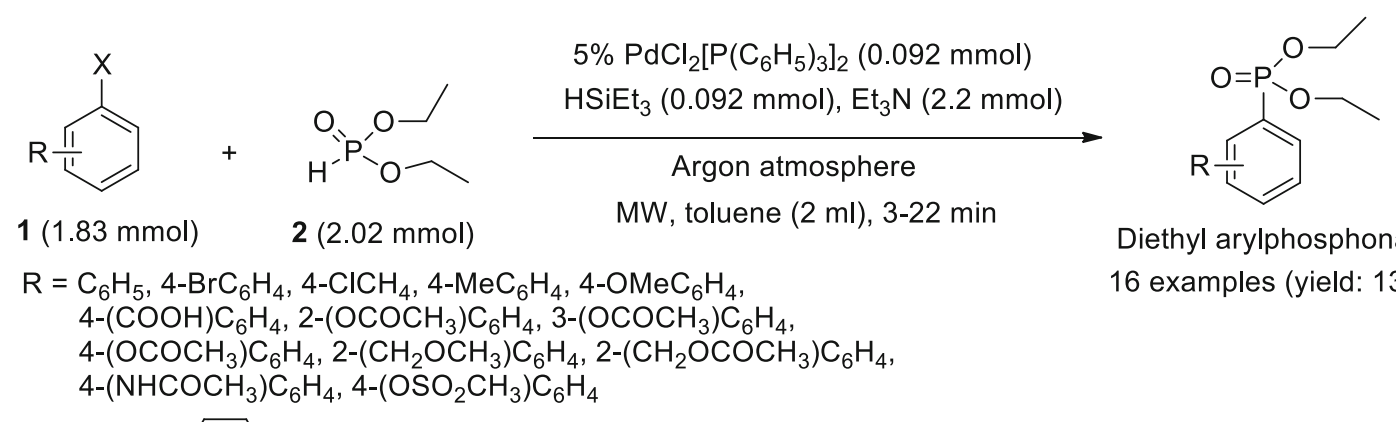

Diethyl arylphosphonate 3

16 examples (yield: 13-96\%)

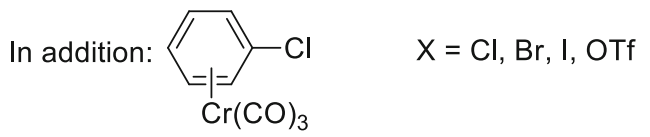

Representatives<smiles>CCOP(=O)(OCC)c1ccc(OC(C)=O)cc1</smiles>

4-(Diethoxyphosphoryl)phenyl acetate

(3a, time: $11 \mathrm{~min}$, yield: $78 \%$ )

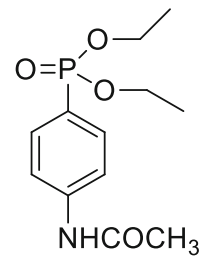

Diethyl (4-acetamidophenyl)phosphonate (3b, time: $3 \mathrm{~min}$, yield: $46 \%$ )<smiles>CCOP(=O)(OCC)c1ccccc1C(C)(C)O</smiles>

3c (time: 8 min, yield: $80 \%$ )

Scheme 3 Synthesis of diethyl arylphosphonates by palladium-catalyzed phosphonation of aryl halides

[21]. Microwave irradiation technique is also regarded as a 'green tool' to save energy consumption [22]. As part of ongoing development of various synthetically important reactions using this technique, the Hirao reaction has also attained quite significant advancement so far. The present article is aimed to offer an up-to-date overview of such developments in synthesizing diverse and functionalized aryl- and vinyl-phosphonates and related derivatives through $\mathrm{P}-\mathrm{C}$ cross-coupling via the microwave-assisted Hirao reaction.

\section{The microwave-assisted Hirao reaction: recent developments}

Like many other significant reactions in organic chemistry, the Hirao reaction has also been studied under the influence of microwave irradiation as reported so far. In 1997, Villemin et al. [23] carried out the coupling reaction between aryl halides (1) and dietheylphosphite (2) in the presence of bis(tripheny1phosphine)palladium dichloride as catalyst in triethyl amine $\left(\mathrm{Et}_{3} \mathrm{~N}\right)$ and toluene under argon atmosphere using microwave irradiation to prepare a variety of diethyl arylphosphonates (3) in moderate to good yields (Scheme 3). The lowest yield (13\%) was observed with 4-iodobenzoic acid and the highest yield (96\%) was isolated in case of 4-iodoanisole. The reactions with aryl iodides gave generally good yields except for the hindered ortho-substituted aryl iodides. $\mathrm{C}-\mathrm{Cl}$ bond activation under the reaction conditions was not observed at all with chlorobenzene, but such activation in case of chlorobenzenetricarbonylchromium was so pronounced that phosphonation of this complex took place feasibly yielding $80 \%$ of the product just at $8 \mathrm{~min}$ without its decomposition. The key advantages of this present protocol over the classical heating methods are the dramatic rate acceleration and easy workup procedure. For example, phosphonation reaction of this complex can also be accomplished via an Arbusov-type reaction under classical heating with the same yield $(81 \%)$ but after $7 \mathrm{~h}$ at reflux [24]. Earlier in 1982, Hirao and his group observed that reaction between aryl halide and dialkylphosphite, catalyzed by palladium( 0 ) complexes, is efficient but requires long time in hours (on average $10 \mathrm{~h}$ ) [12].

In 2006, Jiang and coworkers [25] utilized a modified $\mathrm{Pd}$-catalyzed microwave-assisted Hirao reaction for $\mathrm{P}-\mathrm{C}$ cross-coupling between synthetic 11ß-4-(((trifluoromethyl)sulfonyl)oxy)phenyl-substituted steroid (4) and disubstituted phosphates/phosphine oxides (5) in the presence of $\mathrm{Pd}(\mathrm{OAc})_{2} / \mathrm{dppp} / \mathrm{DIEA} /$ dioxane to produce a new series of phosphorus-functionalized $11 \beta$-aryl-substituted steroids (6) (Scheme 4) with promising progesterone receptor antagonist activity. The stereochemical features of the substrate molecule remained intact within the product. 
The investigators evaluated their progesterone receptor (PR) antagonist activity in a T47D cell-based assay and glucocorticoid receptor (GR) antagonist activity in an A549 cell-based assay. Most of the compounds were potent PR antagonists (nanomolar range), with some showing better selectivity than mifepristone used as a standard. Moreover, some selected compounds showed modest oral progestin antagonist activity in rat uterus. From the viewpoint of structure-activity relationship, it was evident that when $\mathrm{R}^{1}$ and $\mathrm{R}^{2}$ are both alkoxy groups, the change in their size did not affect potencies, while a change in the electronics reduced the potency with a more electron-withdrawing group. It was also observed that substitution at the phenyl ring did not significantly change the potency.

In the same year, Beletskaya et al. [26] introduced a phase-transfer catalysis (PTC) method for the arylation of phosphorylated monosaccharides (8) of pyranose and furanose series bearing $>\mathrm{P}(\mathrm{O}) \mathrm{H}$ moiety in the presence of $\mathrm{PdCl}_{2}\left(\mathrm{PPh}_{3}\right)_{2}$, and microwave irradiation was found to be useful over conventional heating in shortening reaction-time (viz. $3 \mathrm{~h}$ to $14 \mathrm{~min}$ ) (Scheme 5). Conventional heating, in some cases, decomposed the substrate molecules as well. Introduction of PTC technique coupled with the utilization of MW irradiation, thus, successfully offered a facile path for synthesizing theses biologically relevant compounds.

In the next year, Gaumont and his group [27] reported the synthesis of a series of vinylphosphine-borane complexes (12) via palladium-catalyzed C-P cross-coupling of diverse vinyl triflates (10) with secondary diaryl-, dialkyl- and alkylarylphosphine-boranes (11) mainly under heating conditions. However, in some cases they carried out the same reactions using microwave irradiation, and observed

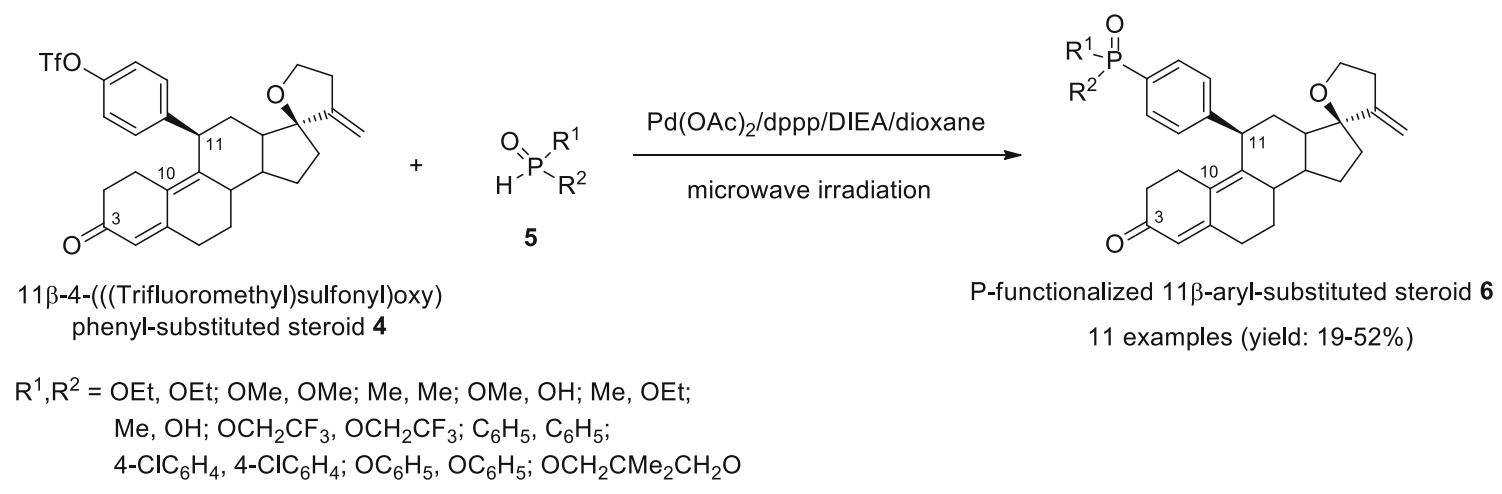

Representatives

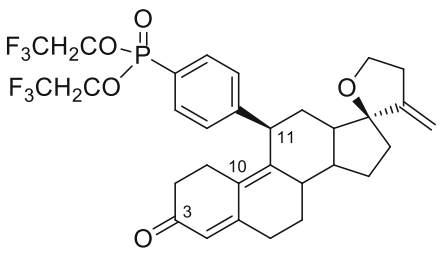

6a (white solid, yield: $30 \%$ )

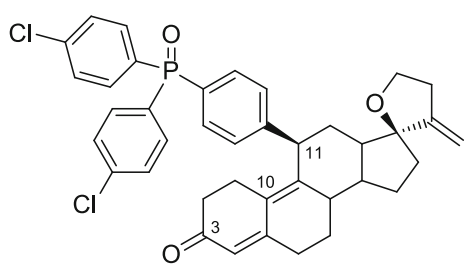

6a (white solid, yield: $42 \%$ )

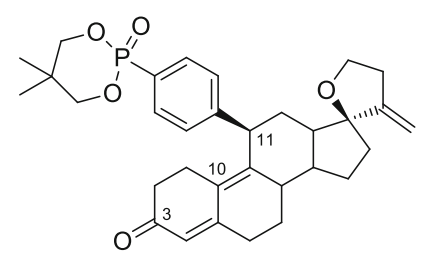

6a (white solid, yield: $33 \%$ )

Scheme 4 Palladium-catalyzed synthesis of phosphorus-functionalized $11 \beta$-aryl-substituted steroids (6)

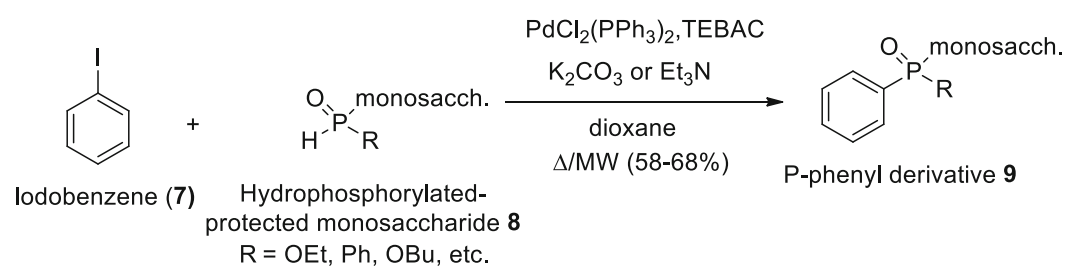

Scheme 5 Palladium-catalyzed P-arylation of hydrophosphoryl derivatives of protected monosaccharides (9) 
Scheme 6 Palladium-catalyzed synthesis of vinylphosphineborane complexes

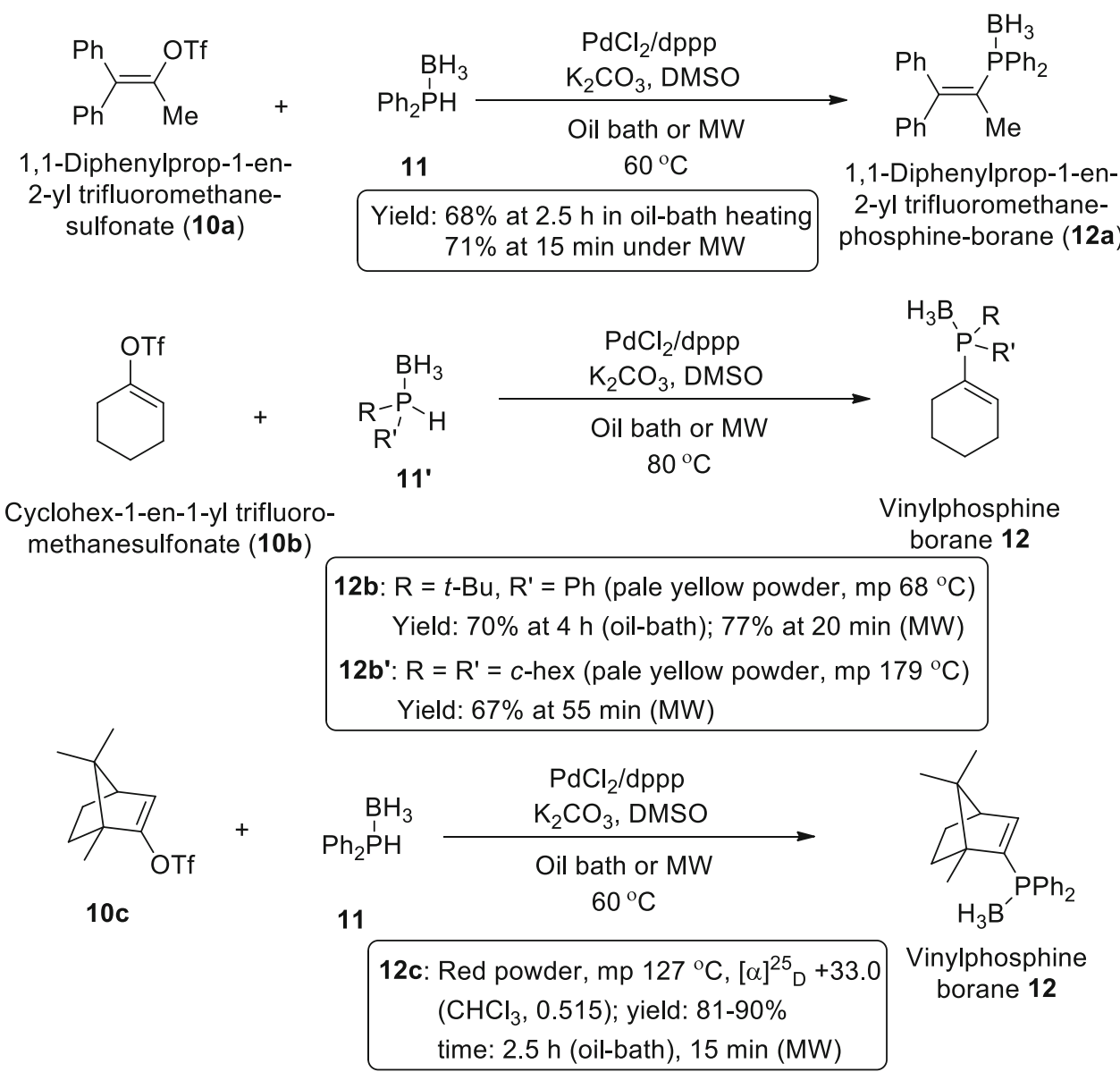

(Scheme 8). This is to mention herein that microwave heating did not affect the stereochemistry of the substrate molecules and remained unchanged in the products as well.

Larhed and his group [29] first time used palladium acetate for the $\mathrm{Pd}(\mathrm{II})$-catalyzed $\mathrm{P}-\mathrm{C}$ coupling reaction between aryl/vinyl boronic acids or trifluoroborates (22) and dialkyl phosphites (2) in the presence of a rigid bidentate ligand dmphen (dmphen $=2$,9-dimethyl-1,10phenanthroline) and $p$-benzoquinone as oxidant without the addition of base or acid under microwave irradiation in DMF solvent (Scheme 9). The reaction was found to proceeds rapidly, just within $30 \mathrm{~min}$, with high chemoselectivity under non-inert conditions. The present investigators extended their protocol to synthesize a Mycobacterium tuberculosis glutamine synthetase (MTB-GS) inhibitor (26). However, the mechanism of this reaction was believed to be different from that of the Hirao reaction; $\mathrm{Pd}(\mathrm{II})$ is the active form of the catalyst, which is regenerated from the $\operatorname{Pd}(0)$ species by the oxidant. Contrary to the $\mathrm{Pd}(0)$-catalyzed $\mathrm{P}$-arylation reactions, this $\mathrm{P}-\mathrm{C}$ coupling can be carried out under neutral to acidic conditions, thereby substantially contributing to the versatility of transition metal-mediated $\mathrm{P}-\mathrm{C}$ bond formations [48]. 


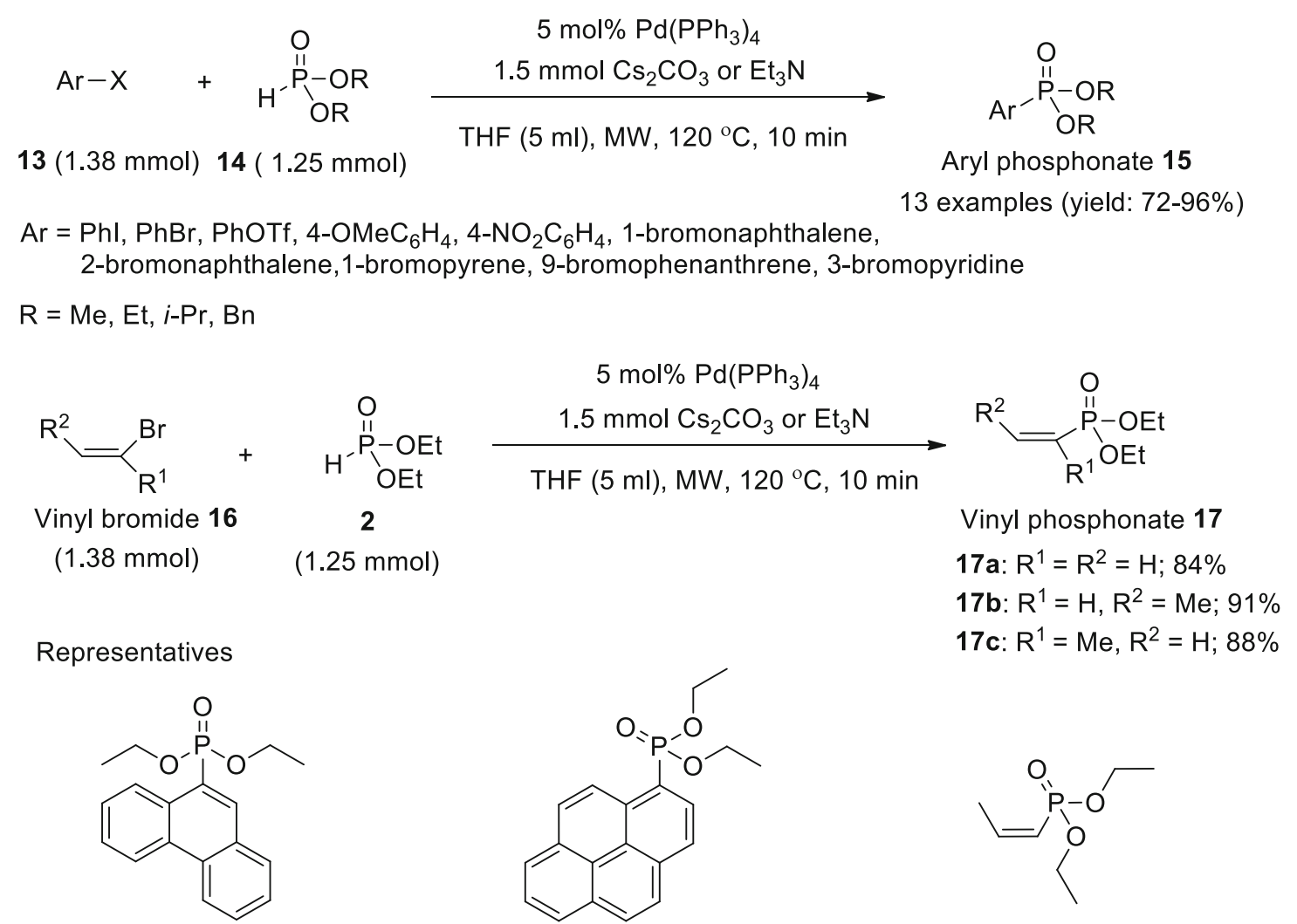

Diethyl phenanthrene-9-yl phosphonate (15a; yield: $72 \%$ )
Diethyl pyrene-1-ylphosphonate (15b; yield: $77 \%$ )
Diethyl Z-1-propen-1-ylphosphonate (17b; yield: 91\%)

Scheme 7 Palladium-catalyzed synthesis of aryl- and vinylphosphonate diesters

Later on, Rummelt et al. [30] developed a green, simple, and novel protocol for cross-coupling of various iodo- and bromobenzoic acids (27) with diphenylphosphine oxide (5) catalyzed by heterogeneous and recyclable $\mathrm{Pd} / \mathrm{C}$ catalytic system in water without the addition of any ligand and additive under microwave irradiation (Scheme 10). The novel series of phosphine oxides can be of further use as ligands for biphasic and water-soluble metal catalysis and organocatalysis. The investigators first performed the reaction with 4-iodobenzoic acid upon conventional heating at $100{ }^{\circ} \mathrm{C}(99 \%$ yield at $1 \mathrm{~h})$, but different halogenated benzoic acids (viz. 4-bromo and 2-iodobenzoic acid) did not yield the desired product under conventional heating. To overcome such a limited scope of the reaction, they used microwave (MW) heating, instead of conventional heating, and became successful in their endeavor. The operational simplicity, fastness of the process, simple workup, and high purity of the desired compounds (28) are some of the key features of the present protocol, which make it a good candidate for application in both laboratory and large-scale synthesis.

Recently, Jablonkai and Keglevich have made a considerable modification of the Hirao reaction [31]; they have observed that the Pd-catalyzed reaction can undergo smoothly under the influence of microwave irradiation in the presence of palladium acetate without any $P$-ligand under solvent-free conditions (Scheme 11). The investigators used a variety of $>\mathrm{P}(\mathrm{O}) \mathrm{H}$ species, such as dialkyl phosphites, ethyl $H$-phenylphosphinate, diphenylphosphine oxide, and dibenzo $[c, e][1,2]$ oxaphosphorine oxide, and a series of aryl bromides in the $\mathrm{P}-\mathrm{C}$ cross coupling reaction. In most of these cases, the corresponding products $\mathbf{3 0}$ were obtained in high yields (73-95\%). The investigators also compared the MW-assisted reactions with those carried out under thermal conditions and the results revealed the specific influence of MW irradiation in accelerating rate of the reaction; better yields were isolated with shorter reaction-time (from hours to minutes) compared to those carried out under conventional heating.

In the very next year, Keglevich group have extended the same reaction with more variety of both the substrates, thereby offering the reaction a general value [32]. Thus such a $P$-ligand-free variation of the microwave-assisted Hirao reaction proves to be a generally useful and ecofriendly method. In their very recent report, Jablonkai and Keglevich have demonstrated an environmentally friendly, catalyst-free and microwave-assisted variation of Hirao 


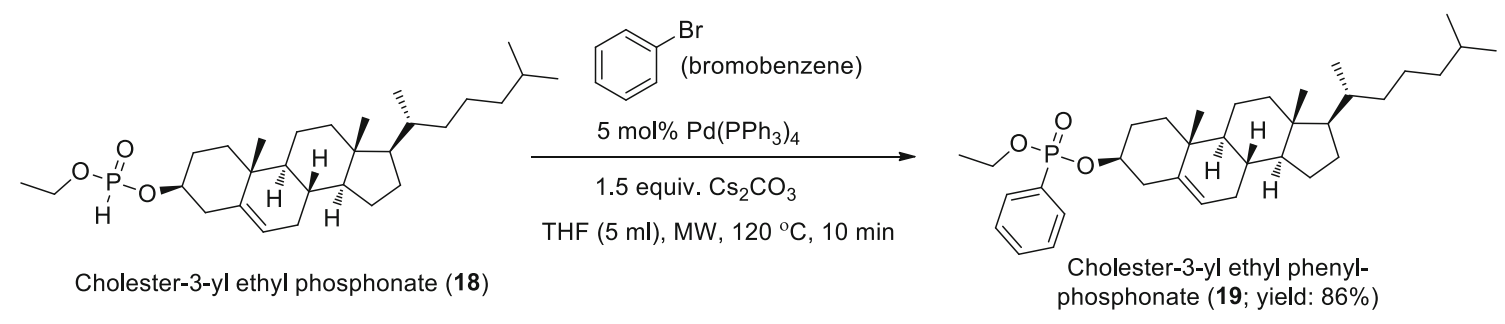

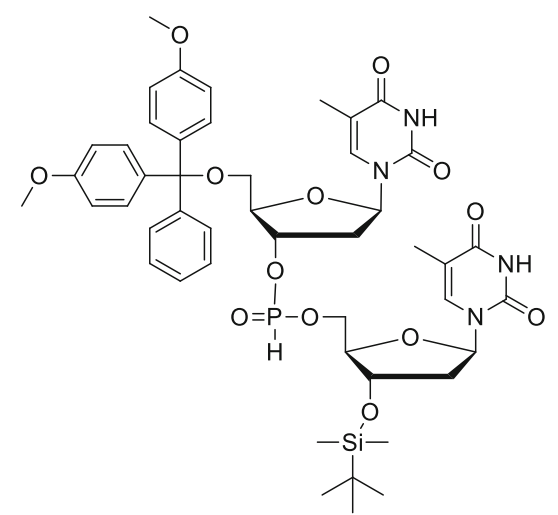

Dinucleoside $\mathrm{H}$-phosphonate derivative (20)

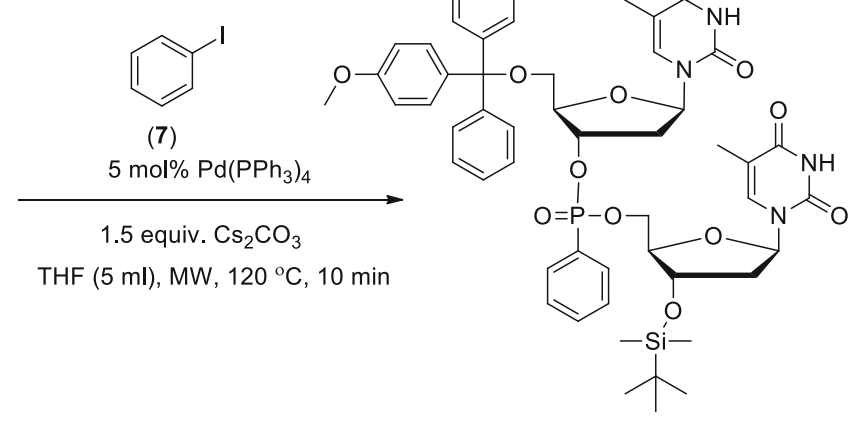

Dinucleoside phenylphosphonate derivative $\mathbf{2 1}$

21- $R_{\mathrm{p}}: 81 \%$

21- $R_{\mathrm{p}}: 84 \%$

Scheme 8 Palladium-catalyzed synthesis of phosphonate diesters linked with nucleoside and cholesteryl moieties

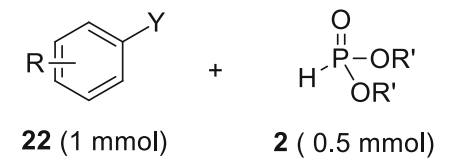

$\stackrel{\mathrm{Pd}(\mathrm{OAc})_{2}(0.2 \mathrm{mmol}) / \mathrm{dmphen}(0.3 \mathrm{mmol})}{p \text {-benzoquinone }(0.5 \mathrm{mmol})}$
$\mathrm{DMF}(2 \mathrm{ml})$, air, $\mathrm{MW}, 100^{\circ} \mathrm{C}, 30 \mathrm{~min}$

(dmphen = 2,9-dimethyl-1,10-phenanthroline)

Aryl phosphonate diester $\mathbf{2 3}$

15 examples (yield: $44-90 \%$ )

$\mathrm{R}=\mathrm{H}, 3-\mathrm{Br}, 4-\mathrm{Br}, 4-\mathrm{COCH}_{3}, 4-\mathrm{COOCH}_{3}, 3-\mathrm{C}_{6} \mathrm{H}_{5}$,

2- $\mathrm{CH}_{3}, 4-\mathrm{CH}_{3}, 3,4-\mathrm{di}-\mathrm{OCH}_{3}$; besides, 1-naphthyl boronic acid

$\mathrm{R}^{\prime}=\mathrm{CH}_{3}, \mathrm{C}_{2} \mathrm{H}_{5} ; \mathrm{Y}=\mathrm{B}(\mathrm{OH})_{2}, \mathrm{BF}_{3} \mathrm{~K}$

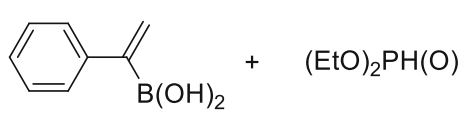

(1-Phenylvinyl) boronic acid (24)

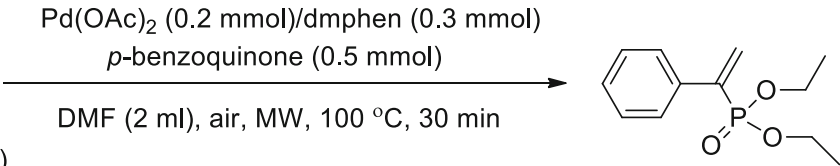

Diethyl (1-phenylvinyl)phosphonate (25)

(yield: $37 \%$ )

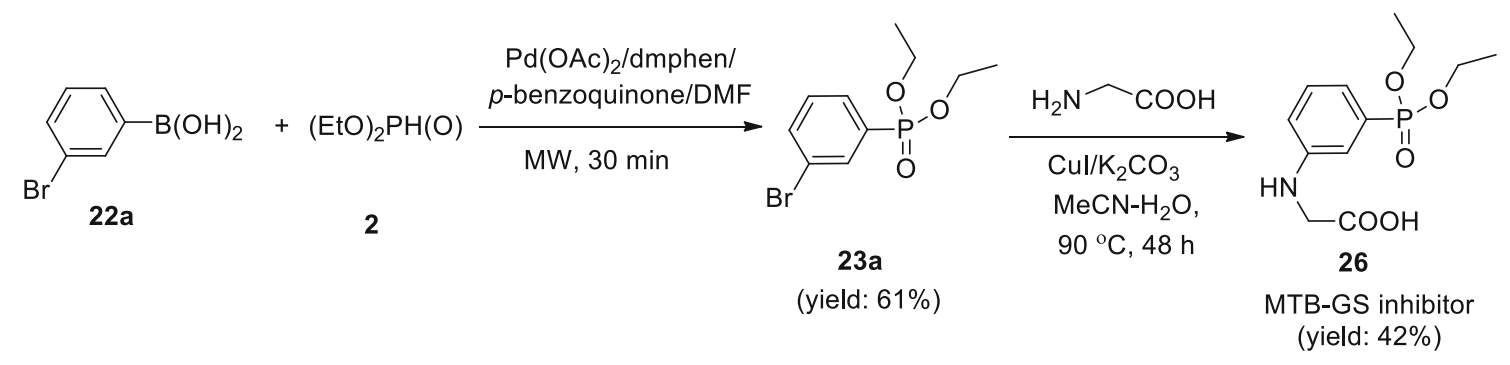

Scheme 9 Pd(II)-catalyzed synthesis of aryl/vinylphosphonate diesters (23 and $\mathbf{2 5}$ ) 


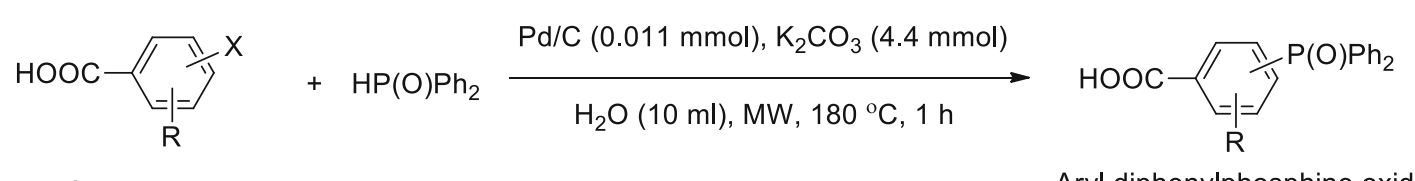

$$
\begin{aligned}
& 27(1.1 \mathrm{mmol}) \quad \mathbf{5} \text { (1.4 mmol) } \\
& \mathrm{R}=\mathrm{H} ; \mathrm{X}=4-\mathrm{Br}, \mathrm{Cl}, \mathrm{I} ; \mathrm{R}=\mathrm{H} ; \mathrm{X}=3-\mathrm{Br}, \mathrm{I} \\
& \mathrm{R}=4-\mathrm{Me} ; \mathrm{X}=3-\mathrm{Br}, \mathrm{I} ; \mathrm{R}=4-\mathrm{OMe} ; \mathrm{X}=3-\mathrm{Br}, \mathrm{I} \\
& \mathrm{R}=3-\mathrm{NH}_{2} ; \mathrm{X}=4-\mathrm{Br} ; \mathrm{R}=\mathrm{H} ; \mathrm{X}^{\prime}=3-\mathrm{Br}, \mathrm{X}^{\prime \prime}=5-\mathrm{I}
\end{aligned}
$$

Aryl diphenylphosphine oxide $\mathbf{2 8}$

12 examples (yield: 41-87\%)

Representatives<smiles>Cc1ccc(C(=O)O)cc1P(=O)(c1ccccc1)c1ccccc1</smiles>

3-(Diphenylphosphoryl)-4-methyl benzoic acid (28a; yield: $81 \%$ )<smiles>Nc1cc(C(=O)O)ccc1P(=O)(c1ccccc1)c1ccccc1</smiles>

4-(Diphenylphosphoryl)-3-amino benzoic acid (28b; yield: $41 \%$ )<smiles>O=C(O)c1cc(P(=O)(c2ccccc2)c2ccccc2)cc(P(=O)(c2ccccc2)c2ccccc2)c1</smiles>

3,5-Bis(diphenylphosphoryl)benzoic acid (28c; pale yellow solid, yield: $74 \%$ )

Scheme 10 Pd/C-catalyzed synthesis of aryl diphenylphosphine oxides (28) in water

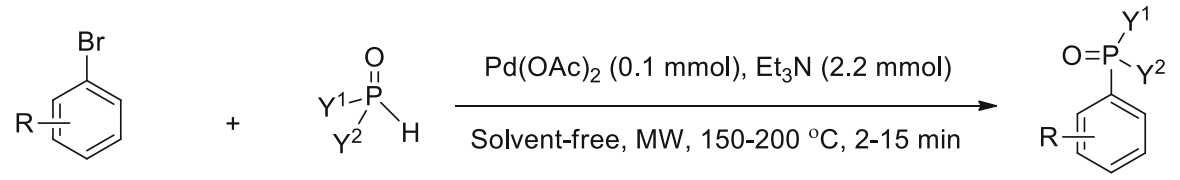

$$
29(2 \mathrm{mmol}) \quad 5(3 \mathrm{mmol})
$$

$\mathrm{R}=\mathrm{H}, 4-\mathrm{Cl}, 4-\mathrm{F}, 4-\mathrm{Me}$, 4-COOEt, 4-COMe

$\mathrm{Y}^{1}, \mathrm{Y}^{2}=\mathrm{OEt}, \mathrm{OEt} ; \mathrm{OBu}, \mathrm{OBu} ; \mathrm{OEt}, \mathrm{Ph} ; \mathrm{Ph}, \mathrm{Ph}$;<smiles>c1ccc2c(c1)COc1ccccc1-2</smiles>

Aryl phosphonates/phosphine oxide $\mathbf{3 0}$ 9 examples (yield: $73-95 \%$ )

Representatives<smiles>O=P(c1ccccc1)(c1ccccc1)c1ccc(F)cc1</smiles>

4-Fluorophenyl diphenylphosphine oxide (30a; pale yellow crystals, $\mathrm{mp} 134-135^{\circ} \mathrm{C}$, yield: $87 \%$ )<smiles>CCCCOP(=O)(OCCCC)c1ccccc1</smiles>

Dibutyl phenylphosphonate (30b, oil, yield: $84 \%$ )
6-Phenyl-6H-dibenzo[c,e][1,2]oxaphosphinine 6-oxide (30c, acetonitrile solvent was required for this entry; crystals, mp $160-161^{\circ} \mathrm{C}$, yield: $84-91 \%$ )

Scheme 11 Ligand-free synthesis of arylphosphonates/phosphine oxides (30)

reaction, which allowed the synthesis of new phosphinoylbenzoic acid derivatives $\mathbf{3 3}$ in water [33]. 4-Bromo and 3-bromobenzoic acids along with 4-iodobenzoic acid underwent $\mathrm{P}-\mathrm{C}$ coupling reactions with diarylphosphine oxides in the absence of any catalyst in water as a solvent under microwave irradiation, and the phosphinoylbenzoic acids obtained were directly converted into their corresponding ethyl esters 33 in good yields (Scheme 12).

\section{Applications of the Hirao products}

The Hirao products (i.e. aryl- and vinyl-phosphonates, phosphine oxides and related derivatives) are compounds of practical importance in industry, agriculture, and medicine as well as in everyday life [34-39]. In addition to their applications as pesticides, detergents, or anticorrosive agents, these phosphorus-containing synthetic compounds 


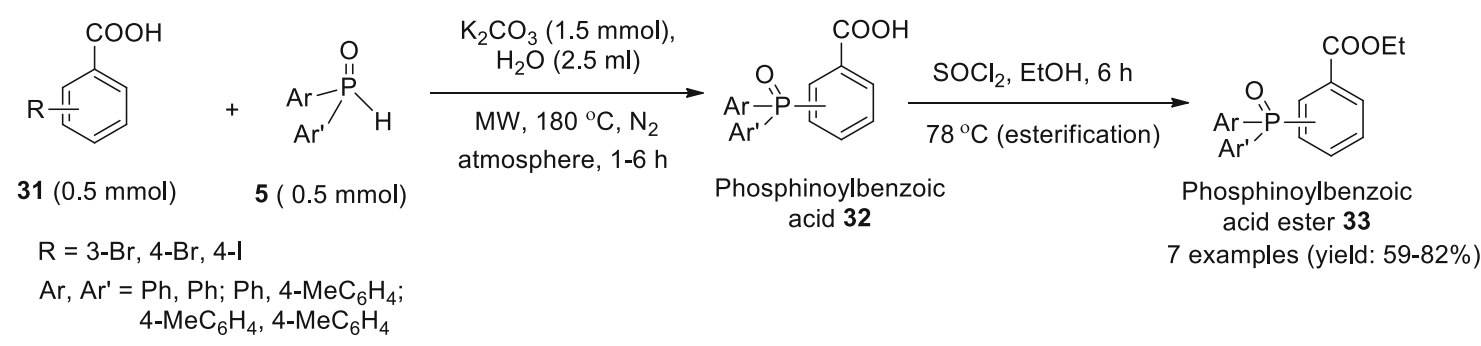

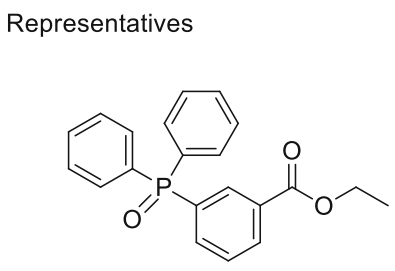

Ethyl 3-(diphenylphosphinoyl)benzoate (33a; yield: $70 \%$ )

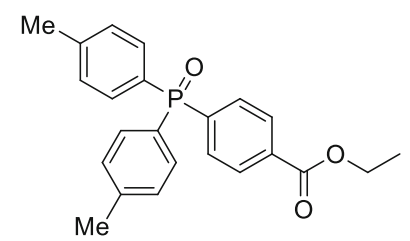

Ethyl 4-[di(4-methylphenyl)phosphinoyl] benzoate (33b; yield: $80 \%$ )

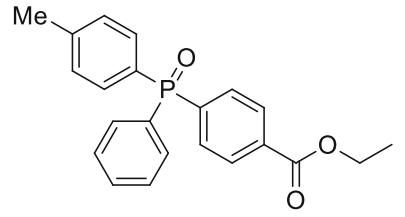

Ethyl 4-[phenyl(4-methylphenyl)phosphinoyl] benzoate (33c; yield: $62 \%$ )

Scheme 12 Catalyst-free synthesis of phosphinoylbenzoate esters (33) in water

Scheme 13 A tree-diagram indicating applications of the Hirao products

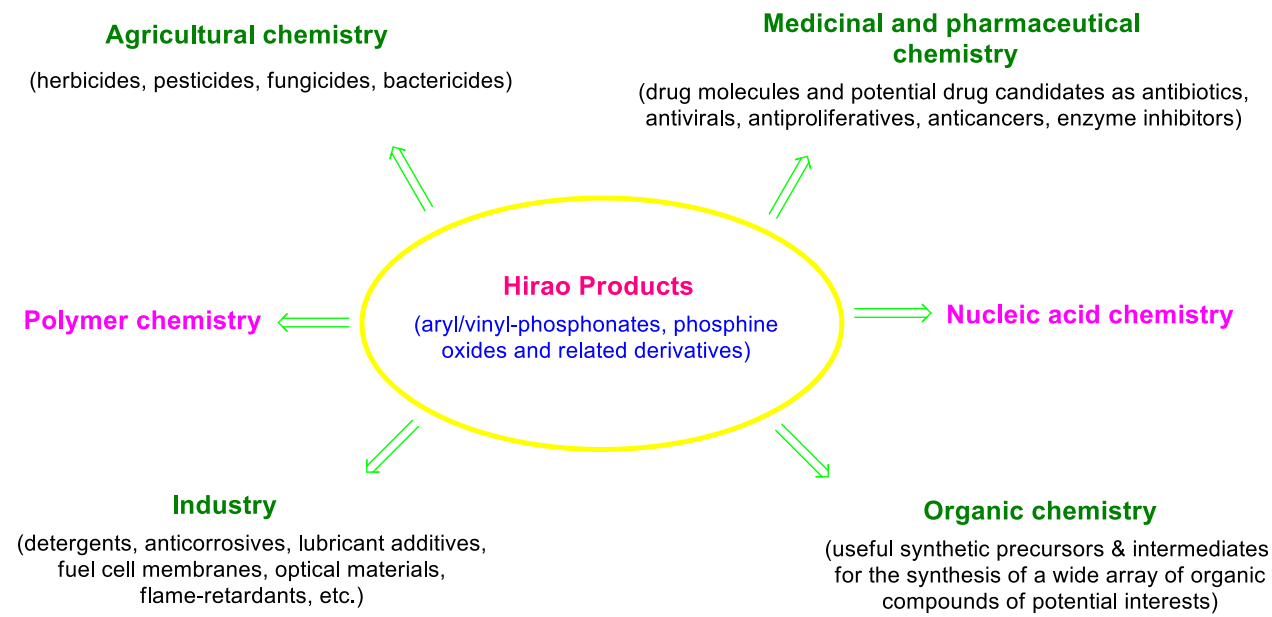

have received a lot of attention both in drug research and in medicinal chemistry due to their great potential in combating diseases and pathological conditions, and curing parasitic infections [40].

Arylphosphonate scaffolds are used in designing fuel cell membranes [39] and materials with special optical properties [41-43]. Arylphosphonates are the phosphonic acids precursors, which can be used for their water-soluble properties and for the synthesis of mixed organic-inorganic materials $[44,45]$. Vinylphosphonates are a well-known class of organophosphorus compounds that are very useful intermediates for the construction of many synthetically and pharmaceutically important compounds including acyclic, carbocyclic, and especially heterocyclic compounds, $\beta$-aminophosphonates and 1,2-epoxyalkylphosphonates [46, 47]. Terminal vinylphosphonates (1-aryl or 1-alkyl ethenylphosphonates) are used as precursors for the synthesis of optically active 1-aryl- or 1-alkyl-substituted ethylphosphonates by asymmetric reduction [48]. They are also useful for the synthesis of 2-(aryl)vinylphosphonates through direct Heck coupling reactions with aryl halides [49]. Vinylphosphonates are involved in the preparation of flame-retardants or polymers, fuels, lubricant additives, as well as intermediates for drugs and agrochemical compounds [50, 51]. Nucleotide- or polyisoprenoid-derived vinylphosphonates possess promising medicinal properties [52, 53]. A series of substituted vinylphosphonates has been recognized as excellent matrix metalloproteinase (MMP-2) inhibitors in vitro, with potential anti-cancer implications [54]. It has, thus, been demonstrated that a $\mathrm{P}-$ $\mathrm{C}$ bond may offer different kinds of biological activities and in accordance to this fact, there has been a growing interest in these classes of organophosphorous compounds in medicinal $[25,52,54,55]$ and nucleic acid chemistry 
[53, 56-60]. A tree-diagram (Scheme 13) summarizes major applications of Hirao products.

\section{Conclusions}

Organic molecules containing phosphorus, now, constitute a major branch of chemistry, and offer fascinating possibilities for their structural, synthetic, and mechanistic study. Organophosphorus compounds find numerous potential applications in the areas of industrial, agricultural, and medicinal chemistry owing to their inherent biological and physical properties. Among a variety of organophosphorus compounds, functionalized aryl- and vinyl-phosphonates and related derivatives show a broad spectrum of applications. The Hirao reaction offers a way to access these compounds, and this reaction has been developed in many folds during the last 35 years. The present article is devoted to offer an insight into the recent developments in the synthesis of diversely functionalized aryl- and vinyl-phosphonates and related derivatives via the Hirao reaction under the influence of microwave irradiation. Microwave irradiation results in rapid rate acceleration of the reaction with excellent stereoselctivity. Application of this 'green tool' for smooth going of the Hirao and Hirao-type reactions has accomplished a considerable advancement in the synthesis of diverse kinds of phosphonate derivatives, and the author hopes this article would be helpful to target readers at large.

Acknowledgments Financial assistance from Council of Scientific and Industrial Research [Grant No. 02(0110)/12/EMR-II], New Delhi, is gratefully acknowledged.

\section{References}

1. Engel R, Cohen JI (eds) (2004) Synthesis of carbon-phosphorus bonds, 2nd edn. CRC Press LLC, Boca Raton

2. Engel R (1977) Phosphonates as analogues of natural phosphates. Chem Rev 77:349-367

3. Hartly R (1996) The chemistry of organophosphorus compounds. Wiley, New York

4. Montchamp J-L (2005) Recent advances in phosphorus-carbon bond formation: synthesis of H-phosphinic acid derivatives from hypophosphorous compounds. J Organomet Chem 690:2388-2406

5. Jablonkai E, Keglevich G (2014) P-C bond formation by coupling reactions utilizing $>\mathrm{P}(\mathrm{O}) \mathrm{H}$ species as the reagents. Curr Org Synth 11:429-453

6. Brahmachari G, Laskar S (2014) Nano-MgO-catalyzed one-pot synthesis of phosphonate ester functionalized 2-amino-3-cyano$4 H$-chromene scaffolds at room temperature. Phosphorus Sulfur Silicon Relat Elem 189:873-888

7. Yuan C, Feng H (1990) Studies on organophosphorus compounds $\mathrm{XL}$. An one-pot procedure for the mono- $o$-alkylation of phosphonic acid: a facile synthesis of alkyl hydrogen $p$-substituted phenylphosphonates. Synthesis pp 140-141

8. Keglevich G, Grün A, Bölcskei A, Drahos L, Kraszni M, Balogh GT (2012) Synthesis and proton dissociation properties of arylphosphonates: a microwave-assisted catalytic Arbuzov reaction with aryl bromides. Heteroatom Chem 23:574-582

9. Brahmachari G (ed) (2015) Green synthetic approaches for biologically relevant heterocycles. Elsevier, Amsterdam

10. Hirao T, Masunaga T, Ohshiro Y, Agawa T (1980) Stereoselective synthesis of vinylphosphonate. Tetrahedron Lett 21:35953598

11. Hirao T, Masunaga T, Ohshiro Y, Agawa T (1981) A novel synthesis of dialkyl arenephosphonates. Synthesis pp 56-57

12. Hirao T, Masunaga T, Yamada N, Agawa T (1982) Palladiumcatalyzed new carbon- phosphorus bond formation. Bull Chem Soc Jpn 55:909-913

13. Prim D, Campagne JM, Joseph D, Rioletti B (2002) Palladiumcatalysed reactions of aryl halides with soft, non-organometallic nucleophiles. Tetrahedron 58:2041-2075

14. Schwan AL (2004) Palladium catalyzed cross-coupling reactions for phosphorus-carbon bond formation. Chem Soc Rev 33:218-224

15. Jablonkai E, Keglevich G (2014) Advances and new variations of the Hirao reaction. Org Prep Proc Int 46:281-316

16. Gedye R, Smith F, Westaway K, Ali H, Baldisera L, Laberge L, Rousell J (1986) The use of microwave ovens for rapid organic synthesis. Tetrahedron Lett 27:279-282

17. Giguere RJ, Bray TL, Duncan SM, Majetich G (1986) Application of commercial microwave ovens to organic synthesis. Tetrahedron Lett 27:4945-4948

18. Hayes BL (2004) Recent advances in microwave-assisted synthesis. Aldrichimica Acta 37:66-77

19. Kranjc K, Kočevar M (2010) Microwave-assisted organic synthesis: general considerations and transformations of heterocyclic compounds. Curr Org Chem 14:1050-1074

20. Elander N, Jones JR, Lu S-Y, Stone-Elander S (2000) Microwave-enhanced radiochemistry. Chem Soc Rev 29:239-249

21. Bandyopadhyay D, Banik BK (2015) Microwave-induced synthesis of heterocycles of medicinal interests. In: Brahmachari $G$ (ed) Green synthetic approaches for biologically relevant heterocycles. Elsevier, Amsterdam, pp 517-557

22. Keglevich G (2015) Application of microwave irradiation in the synthesis of P- heterocycles. In: Brahmachari G (ed) Green synthetic approaches for biologically relevant heterocycles. Elsevier, Amsterdam, pp 559-570

23. Villemin D, Jaffrés P-A, Siméon F (1997) Rapid and efficient phosphonation of aryl halides catalysed by palladium under microwaves irradiation. Phosphorus Sulfur Silicon Relat Elem 130:59-63

24. Chauvin R (1990) Reaction of haloarenetricarbonylchromium with trimethylphosphite: palladium-catalyzed Arbuzov reaction versus arene displacement by trimethylphosphite. J Organometal Chem 387:C1-C4

25. Jiang W, Allan G, Fiordeliso JJ, Linton O, Tannenbaum P, Xu J, Zhu P, Gunnet J, Demarest K, Lundeen S, Sui Z (2006) New progesterone receptor antagonists: phosphorus-containing $11 \beta$ aryl-substituted steroids. Bioorg Med Chem 14:6726-6732

26. Beletskaya IP, Karlstedt NB, Nifant'ev EE, Khodarev DV, Kukhareva TS, Nikolaev AV, Ross AJ (2006) Palladium-catalyzed P-arylation of hydrophosphoryl derivatives of protected monosaccharides. Russ J Org Chem 42:1780-1785

27. Julienne D, Lohier J-F, Delacroix O, Gaumont A-C (2007) Palladium-catalyzed C-P coupling reactions between vinyl triflates and phosphine-boranes: efficient access to vinylphosphine-boranes. J Org Chem 72:2247-2250

28. Kalek M, Ziadi A, Stawinski J (2008) Microwave-assisted palladium-catalyzed cross- coupling of aryl and vinyl halides with H-phosphonate diesters. Org Lett 10:4637-4640

29. Andaloussi M, Lindh J, Sävmarker J, Sjöberg PJR, Larhed M (2009) Microwave-promoted Palladium(II)-catalyzed C-P bond 
formation byusing arylboronic acids or aryltrifluoroborates. Chem Eur J 15:13069-13074

30. Rummelt SM, Ranocchiari M, van Bokhoven JA (2012) Synthesis of water-soluble phosphine oxides by Pd/C-catalyzed P-C coupling in water. Org Lett 14:2188-2190

31. Jablonkai E, Keglevich G (2013) P-ligand-free, microwave-assisted variation of the Hirao reaction under solvent-free conditions; the P-C coupling reaction of $>\mathrm{P}(\mathrm{O}) \mathrm{H}$ species and bromoarenes. Tetrahedron Lett 54:4185-4188

32. Keglevich G, Jablonkai E, Balàzs LB (2014) A "green” variation of the Hirao reaction: the P-C coupling of diethyl phosphite, alkyl phenyl- $\mathrm{H}$-phosphinates and secondary phosphine oxides with bromoarenes using a P-ligand-free $\mathrm{Pd}(\mathrm{OAc}) 2$ catalyst under microwave and solvent-free conditions. RSC Adv 4:22808-22816

33. Jablonkai E, Keglevich G (2015) Catalyst-free P-C coupling reactions of halobenzoic acids and secondary phosphine oxides under microwave irradiation in water. Tetrahedron Lett 56:1638-1640

34. Minami T, Motoyoshiya J (1992) Vinylphosphonates in organic synthesis. Synthesis pp 333-349

35. Zhou T, Chen ZC (2001) Hypervalent iodine in synthesis. 52. Palladium- catalyzed arylation of $O, O$-dialkyl phosphites with diaryliodonium salts: a convenient method for synthesis of arylphosphonates. Synth Commun 31:3289-3294

36. Jiao XY, Bentrude WG (2003) A facile route to vinyl- and arylphosphonates by vinyl and aryl radical trapping with $(\mathrm{MeO})_{3} \mathrm{P}$. J Org Chem 68:3303-3306

37. Maffei M (2004) Transition metal-promoted syntheses of vinylphosphonates. Curr Org Synth 1:355-375

38. Ebdon JR, Price D, Hunt BJ, Joseph P, Gao F, Milnes GJ, Cunliffe LK (2000) Flame retardance in some polystyrenes and poly(methyl methacrylate)s with covalently bound phosphoruscontaining groups: initial screening experiments and some laser pyrolysis mechanistic studies. Polym Degrad Stab 69:267-277

39. Bock T, Moehwald H, Muelhaupt R (2007) Arylphosphonic acidfunctionalized polyelectrolytes as fuel cell membrane material. Macromol Chem Phys 208:1324-1340

40. Kafarski P, Lejczak B (1991) Biological activity of aminophosphonic acids. Phosphorus Sulfur Silicon Relat Elem 63:193-215

41. Zakeeruddin SM, Nazeeruddin MK, Pechy P, Rotzinger FP, Humphry-Baker R, Kalyanasundaram K, Grätzel M, Shklover V, Haibach T (1997) Molecular engineering of photosensitizers for nanocrystalline solar cells: synthesis and characterization of $\mathrm{Ru}$ dyes based on phosphonated terpyridines. Inorg Chem 36:5937-5946

42. Belfield KD, Chinna C, Schafer KJ (1997) New NLO stilbene derivatives bearing phosphonate ester electron-withdrawing groups. Tetrahedron Lett 38:6131-6134

43. Ogawa T, Usuki N, Ono N (1998) A new synthesis of $\pi$-electron conjugated phosphonates and phosphonic bis(diethylamides) and their SHG activities. J Chem Soc Perkin Trans 1:2953-2958

44. Schull TL, Fettinger JC, Knight DA (1995) The first examples of an aryl ring substituted by both phosphine and phosphonate moieties: synthesis and characterization of the new highly water-soluble phosphine ligand $\mathrm{Na}_{2}\left[\mathrm{Ph}_{2} \mathrm{P}\left(\mathrm{C}_{6} \mathrm{H}_{4}-p-\mathrm{PO}_{3}\right)\right] .1 .5 \mathrm{H}_{2} \mathrm{O}$ and platinum(II) complexes. J Chem Soc Chem Commun pp 1487-1488

45. Lelievre S, Mercier F, Mathey E (1996) phosphanorbornadienephosphonates as a new type of water-soluble phosphines for biphasic catalysis. J Org Chem 61:3531-3533
46. Janecki T, Kedzia J, Wasek T (2009) Michael additions to activated vinylphosphonates. Synthesis 1227-1254

47. Dembitsky VM, A. Al-Quntar AA, Haj-Yehia A, Srebnik M (2005) Recent synthesis and transformation of vinylphosphonates. Mini Rev Org Chem 2:91-109

48. Wang DY, Hu XP, Deng J, Yu SB, Duan ZC, Zheng Z (2009) Enantioselective synthesis of chiral $\alpha$-aryl or $\alpha$-alkyl substituted ethylphosphonates via Rh-catalyzed asymmetric hydrogenation with a P-stereogenic BoPhoz-type ligand. J Org Chem 74:4408-4410

49. Tarabay J, Al-Maksoud W, Jaber F, Pinel C, Prakash S, Djakovitch L (2010) Synthesis of diethyl 2-(aryl)vinylphosphonate by the Heck reaction catalysed by supported palladium catalysts. Appl Catal A 388:124-133

50. Price D, Pyrah K, Hull TR, Milnes GJ, Ebdon JR, Hunt BJ, Joseph P (2002) Flame retardance of poly(methyl methacrylate) modified with phosphorus-containing compounds. Polym Degrad Stab 77:227-233

51. Jin S, Gonsalves KE (1998) Synthesis and characterization of functionalized poly( $\varepsilon$ - caprolactone) copolymers by free-radical polymerization. Macromolecules 31:1010-1015

52. Holstein SA, Cermak DM, Wiemer DF, Lewis K, Hohl RJ (1998) Phosphonate and bisphosphonate analogues of farnesyl pyrophosphate as potential inhibitors of farnesyl protein transferase. Bioorg Med Chem 6:687-694

53. Lazrek HB, Rochdi A, Khaider H, Barascut JL, Imbach JL, Balzarini J, Witvrouw M, Pannecouque C (1998) Clercq ED (1998) Synthesis of $(Z)$ and $(E) \alpha$-alkenyl phosphonic acid derivatives of purines and pyrimidines. Tetrahedron 54:3807-3816

54. Al-Quntar AAA, Baum O, Reich R, Srebnik M (2004) Recently synthesized class of vinylphosphonates as potent matrix metalloproteinase (MMP-2) inhibitors. Arch Pharm 337:76-80

55. Ullrich KJ, Rumrich G, Burke TR, Shirazie-Beechey SP, Lang G-L (1997) Interaction of alkyl/arylphosphonates, phosphonocarboxylates and diphosphonates with different anion transport systems in the proximal renal tubule. J Pharmacol Exp Ther 283:1223-1229

56. Agarwal KL, Riftina F (1979) Synthesis and enzymatic properties of deoxyribooligonucleotides containing methyl and phenylphosphonate linkages. Nucleic Acids Res 6:3009-3024

57. Harnden MR, Parkin A, Parratt MJ, Perkins RM (1993) Novel acyclonucleotides: synthesis and antiviral activity of alkenylphosphonic acid derivatives of purines and a pyrimidine. J Med Chem 36:1343-1355

58. Abbas S, Bertram RD, Hayes CJ (2001) Commercially available 5 -DMT phosphoramidites as reagents for the synthesis of vinylphosphonate-linked oligonucleic acids. Org Lett 3:3365-3367

59. Engels JW, Parsch J (2005) Nucleic acid drugs. In: Dingermann T, Steinhilber D, Folkers G (eds) Molecular biology in medicinal chemistry. Wiley-VCH Verlag $\mathrm{GmbH} \&$ Co., Chichester, pp 153-178

60. Zmudzka K, Johansson T, Wojcik M, Janicka M, Nowak M, Stawinski J, Nawrot B (2003) Novel DNA analogues with 2-, 3and 4-pyridylphosphonate internucleotide bonds: synthesis and hybridization properties. N J Chem 27:1698-1705 